\title{
LA DIOSA NÜWA Y LA VIDA DE LAS MUJERES LOCA- LES: UN ESTUDIO BASADO EN LA EXPLORACIÓN DEL MITO DE NÜWA Y EL PORTADOR EN EL DISTRITO SHEXIAN, PROVINCIA HEBEI
}

\begin{abstract}
NÜWA GODDESS AND THE LIFE OF LOCAL WOMEN: A STUDY BASED ON THE EXPLORATION OF NÜWA MYTH AND THE BEARER IN THE DISTRICT OF SHEXIAN, PROVINCE OF HEBEI
\end{abstract}

Shuhua, Yan, 女娲与当地女性生活

Fan Yu

Universidad de Sevilla (España)

La sociedad está formada por personas. Los hombres y las mujeres son elementos importantes de la sociedad. No obstante, en las diferentes etapas del desarrollo social, los hombres y las mujeres juegan diferentes roles, lo que inevitablemente conduce a que adquieran diferentes estatus sociales. La sociedad humana ha experimentado un proceso de transición, del matriarcado al patriarcado. Sin embargo, las mujeres, por su capacidad de engendrar vida, siempre han sido respetadas y amadas. Desde Gea, en la mitología occidental, hasta Nüwa - madre de la humanidad - en la leyenda oriental, las mujeres en los mitos de la creación muestran una fuerza poderosa y son portadoras del amor universal.

En el distrito de Shexian, provincia Heibei, se ubica el Palacio de Nüwa donde, según las leyendas locales, la Diosa creó seres humanos y animales con tierra amarilla y reparó el cielo con la piedra de cinco colores. Es el edificio más antiguo y grande que se consagró a la ofrenda de sacrificios a Nüwa. Cada año se celebran dos ceremonias grandiosas, la ceremonia oficial y la celebración popular, ambos buenos momentos para 
la congregación de peregrinos. De este modo, el mito de Nüwa y su plasmación física - el Palacio de Nüwa - están entrelazados con la economía y la cultura local, que se desarrollan interactuando conjuntamente. Las creencias y la arquitectura locales dotan a Nüwa de una sagrada solemnidad y le conceden el respeto que se merece por parte de la gente. Los mitos y los templos dieron al pueblo consuelo espiritual y apoyo fiel. Después de la comparación de varias ceremonias en distintos distritos por toda China, la del distrito de Shexian es la más representativa y típica.

En la actualidad, nadie ha obtenido grandes resultados en lo referente a la investigación de la Diosa Nüwa y su relación con la vida de las mujeres locales. En esta tesis doctoral, se analiza la influencia de la leyenda y de la fe en Nüwa y su asentada cultura en la vida de las mujeres, no solo en los aspectos positivos sino también en los negativos. Haciendo pleno uso de las ventajas del mito de Nüwa y eludiendo sus lados débiles, asoma la intención de mejorar la situación irremplazable de las mujeres en la construcción de una sociedad armoniosa hoy en día.

Desde el plano de la investigación, se presentan cuatro aspectos en esta disertación. En primer lugar, se expone el contenido y las características del mito de Nüwa específicos en el distrito de Shexian, así como las particularidades y los detalles del Palacio de Nüwa, portador del mito, clasificado como una de las atracciones turísticas de máximo nivel en China. Sobre esta base, se analiza la relación entre las historias de Nüwa y su templo, y se descubre el significado realista que ambos representan en la vida de la gente local. En general, los mitos se originan en la realidad, y a menudo reflejan la vida real o incluso utopías derivadas de las desgracias de la Antigüedad. En este sentido, la autora discute en esta parte la encarnación de Nüwa, y explora el significado social desde el origen del mito, que infunde el espíritu de optimismo y el amor generoso que Nüwa nos trae.

En segundo lugar, esta disertación describe los elementos socio-regionales relacionados con Nüwa, incluidas las ceremonias conmemorativas, la magnificencia de la peregrinación, los peregrinos, el discurso ceremonial, las ceremonias familiares y la participación de las mujeres en estas actividades. Aparte de eso, también se mencionan en este capítulo las influencias que ejercen el Palacio de Nüwa y las ceremonias en la economía local, en la reputación, en el nivel de vida y en las mujeres. En los últimos años, las ceremonias no sólo han promovido el desarrollo de la economía local, sino también muchas actividades tradicionales. Por tanto, las costumbres de los habitantes revisten un valor un valor académico. De hecho, Nüwa y sus mitos relevantes se han convertido en un aspecto indispensable en los estudios académicos, puesto que ya están arraigados en 
la vida de los residentes del distrito de Shexian, es decir, muchos hábitos y costumbres diarios están estrechamente relacionados con la imagen de Nüwa.

La tercera sección se enfoca en las mujeres locales. Desde la perspectiva de la vida cotidiana, las familias, las actividades colectivas y culturales, se estudian las particularidades de la vida de las mujeres locales y se encuentran los factores influyentes que el mito de Nüwa aporta. Al asociar la cultura Nüwa con la sociedad contemporánea, esta parte tiene el objetivo de mejorar la vida de las mujeres locales con la inspiración del mito de Nüwa.

Por último, la autora analiza cómo el mito de Nüwa y su manifestación reconstruyen la vida de las mujeres locales. Proponiéndose la investigación de dicha reconstrucción, esta parte analiza el mito desde las perspectivas positiva y negativa del pensamiento dialéctico, para concluir que la popularidad de Nüwa no solo tiene una influencia positiva en las mujeres locales, sino que también incide en las supersticiones, y en la vulgarización simplificadora de su imagen. En el curso de la investigación, la autora anota que las actitudes más o menos racionales hacia el mito de Nüwa dependen de la edad y de los antecedentes educativos de los fieles. Por lo tanto, esta obra sostiene la opinión de que se debe enfatizar su influencia en el auto-estímulo, la experiencia de la vida y la autoconciencia de las mujeres. Más importante aún, la orientación hacia el valor de las mujeres debe ser dirigida por el espíritu indomable de Nüwa, y las mujeres deben encontrar la posición social más apropiada donde puedan desempeñar un papel más trascendental en la construcción de una sociedad mejor.

Para dar fin a su tesis, concluye la autora con tres proposiciones basadas en los análisis antecedentes. La primera proposición es que el estatus social de las mujeres no es otorgado por otros grupos sociales, sino que es reconocido y aceptado socialmente por sus propios méritos y por su contribución a la comunidad. La segunda proposición se centra en la coordinación de los diferentes poderes en competencia entre hombres y mujeres, y admite que las diferencias entre mujeres y hombres sí existen, por lo que el potencial de ambos debe ser plenamente explotado asumiendo las respectivas responsabilidades. La tercera proposición es que el amor maternal, especialmente en las aldeas, es un gran asunto para el estudio, ya que las mujeres tienen la mayor responsabilidad en la educación familiar e incluso en el futuro de toda la nación.

En conclusión, esta tesis no se limita a ofrecer material conocido, sino que nos propone un nuevo enfoque al combinar el mito de Nüwa con la investigación de campo. Por un lado, la autora ha descubierto las influencias que ejercen el mito de Nüwa y su templo en la vida de las mujeres y 
ha aclarado las influencias positivas y negativas. Por otro lado, responde a la intención de perfeccionar las actividades conmemorativas de Nüwa, con el propósito de optimizar la vida de las mujeres locales, lo cual suma un sentido práctico a este estudio mitológico. 